\title{
Debating the value of twinning in the United Kingdom: the need for a broader perspective
}

\author{
Holly Eva Ryan ${ }^{1} \cdot$ Caterina Mazzilli ${ }^{1}$
}

Accepted: 27 February 2021

(c) Crown 2021

\begin{abstract}
The twinning model has been used to develop a wide array of political, economic and cultural relationships that connect communities and institutions in the United Kingdom with counterparts overseas. However, where local governments were once among the most ardent promoters of twinning, years of austerity coupled with changing processes of financial rationalisation, have led many councils to question the value of these relationships. Today, fewer British local authorities are taking up new twinnings and some have even been involved in a process of quiet 'untwinning'. This paper takes pause to examine what might be lost with this set of changes-it asks: just what is of value of twinning? Taking a cue from ongoing debates in the field of cultural policy studies, it advocates for a broadening and deepening of the operational concept of 'public value' to better account for the manifold ways that twinning can deliver pro-social benefits to British communities and their partners.
\end{abstract}

Keywords Twinning $\cdot$ Sister cities · Community linking $\cdot$ Public value $\cdot$ United Kingdom

\section{Introduction}

'Twinning' refers to the construction of formal or informal ties between towns, cities, institutions or localities usually located in different countries. Inspired in part by the earlier pacifist, anarchist and social reformist movements of the late nineteenth century, the practice of twinning only really blossomed and spread after World War II, as national governments in Europe sought to promote peace and cooperation among communities torn apart by recent conflict (Clarke 2009; Gaspari 2002). The twinnings of the post-war period centred on family and schools-based exchanges

\author{
Holly Eva Ryan \\ h.ryan@qmul.ac.uk \\ Caterina Mazzilli \\ c.mazzilli@qmul.ac.uk \\ 1 Queen Mary University of London, London E1 4NS, UK
}


with a substantial cultural content (Handley 2006). In this sense, they may be understood as an experiment in applied cultural diplomacy, targeted at building a 'positive peace' (Galtung 1964) in the context of beleaguered, fragile, and divided national communities. The intra-European twinning project experienced a number of additional boosts in the twentieth century. These largely followed the progress of expansion of the European Economic Community and later the European Union, together with other political events such as the fall of the Berlin Wall in 1991 and the corresponding 'opening up' of Eastern Germany and the former Soviet bloc.

As of 2006, there were over 2000 formal twinnings where one partner was a UK town or locality. Whilst the vast majority of these were intra-European partnerships, some $25 \%$ saw a British locality partnering with a constituency outside of Europe (Handley 2006). This reflected a general trend through which, from the late 1970s to the mid 2000s, twinning became a model with a more global uptake and a muchbroadened agenda. Formal-that is, 'council-endorsed'-links were complemented by numerous informal or de-facto twinnings, friendship ties and project-based activities, involving not just towns or cities but also trade unions, cooperatives, schools, hospitals, as well as other public services and technical bodies (Ryan 2020a, b). In this respect, twinning can no longer be understood solely in terms of municipal diplomacy aimed at bolstering the "high politics" of peace and international cooperation. In recent decades, it has evolved into a more inclusive and amorphous practice through which local and intermediary levels of government, as well as a wide array of civil society groups have been able to pursue their own agendas and passions. Today's twinning and friendship associations include diasporic communities connecting with 'home', educators seeking to foster intercultural learning, artists pursuing collaborations with counterparts abroad, activists extending solidarity or material assistance to besieged communities overseas as well as development practitioners seeking alternative strategies for technical cooperation with the Global South (ibid.). For this reason, contemporary British twinning practice can be difficult to categorise. On the one hand it sits, sometimes uneasily, at the intersections of state and civic/voluntary action. On the other, it bridges cultural policy with other agendas such as economic development and trade, peace-building and global education.

Despite the incredibly rich variety of activity that has been initiated under the banner of twinning within and beyond British borders, the practice has recently come under increasing scrutiny from politicians, media commentators and parts of the public. Where local governments were formerly the main promoters of twinning, ever scarcer resources in a climate of austerity, coupled with changing processes of financial rationalisation at the municipal level, have led many city, district and county councils to question the value of these relationships. Today, fewer local councils in the UK are taking up new twinnings with overseas partners and some have even been involved in a process of silent 'untwinning', whereby the resources, officers and institutional knowledge required to maintain international relationships are repurposed and/or lost amid wider processes of restructuring and slimlining. 
Based on three years of in-depth research, comprising of over 60 semi-structured interviews ${ }^{1}$ with a variety of twinning associations and friendship links ${ }^{2}$, umbrella organisations $^{3}$ and local authorities, this paper takes pause to examine what has-or might be-lost with this set of changes. It seeks to answer the questions: just what is of value of twinning? and, how should this value be conceptualised? Taking a cue from ongoing debates in the field of cultural policy studies, it advocates for a broadening and deepening of the operational concept of 'public value' to better account for the manifold ways that twinning can deliver prosocial benefits to British communities and their overseas counterparts. In particular, we develop a four-pronged typology of value against which most twinning activities can be mapped.

\section{Evidencing worth? A cautionary tale from cultural policy studies}

The public value of twinning in the British context is something that has scarcely been examined by researchers. However, the concept and question of public value has been extensively discussed and dissected in the broader field of cultural policy analysis. Superficially, public value can be perceived to be about the politics of 'value for money' and the idea of economic returns on government investment (Walmsley and Oliver 2011). However, cultural policy scholars have pushed back against this narrow economistic framing, challenging it on both methodological and normative grounds. The debates that have played out in the arena of cultural policy studies are of the utmost relevance to those engaged in twinning practice today, providing a cautionary tale for groups facing accelerated pressures to "prove their worth'.

Cultural policy can be understood as the sum of a government's activities with respect to the arts (Mulcahy 2006). This includes the for-profit cultural industries, museums and galleries, popular and folkloric activities as well as a range of projects in education, heritage and conservation (Ibid). For much of the twentieth century, British cultural policy was guided by somewhat abstract notions such as national prestige and excellence (Holden 2006). However, in recent decades, cultural policy discourse has shifted, with the arts and cultural events coming to be regarded as economic activities capable of generating national income (Belfiore 2004). Alongside this, there has been a significant increase in the amount of private investment in the arts; as well as a much broader embrace of targets, data management and impact measurement (O’Brien 2013; Crossick and Kaszynska 2016).

Authors trace these shifts back to reforms initiated by Margaret Thatcher's government during the 1980s and particularly the New Public Management (NPM) framework pursued at this juncture (Stevenson et al. 2010; Hood 1991). Proponents of NPM posited that a reduced role for government, increased marketization and

\footnotetext{
${ }^{1}$ Participants were selected on the basis of their immersion into the 'field' (qua Bourdieu) of twinning practice. We have changed all participants' names in order to protect their identities.

${ }^{2}$ We use the term 'twinning association' to designate a formal (that is, council-endorsed) twinning and 'friendship link' to designate an informal twinning.

${ }^{3}$ We use the term "umbrella organisation" to describe any governmental or non-governmental entity that plays the role of a knowledge bank, coordinating body or 'switchboard' for twinning relationships.
} 
greater reliance on competition, incentives and private contractual arrangements would result in improved outcomes for most policy sectors. Belfiore (2004) explains how, in the wider context of the Thatcherite reforms of the 1980s, acquiescence to NPM was more a matter of survival for the British cultural sector than a choice. In a climate of great uncertainty about future public funding, it became a priority for arts organisations to develop cases for continued state support. Hence, a series of increasingly transactional arguments for arts subsidies began to circulate. These were premised on the idea that the cultural and creative sector could make a strong 'return' on the government's 'investment', due to its potential for 'job creation, tourism promotion, invisible earnings, and its contribution to urban-as well as socialregeneration" (Belfiore 2004, p. 184).

Whilst some scholars celebrated NPM as a model of efficiency (Hood 1991; Osborne and Gaebler 1992), others were considerably less effusive in their analysis, pointing to the framework's inability to meet certain public sector principles relating to scrutiny, accountability and inclusivity (Feldman and Khademian 2001; Beck Jørgensen 1999). Within the arts and cultural sector specifically, there were severe criticisms levelled at the kinds of methodologies adopted to track and trace art value. For example, the exchange-value of art objects was increasingly favoured over their use and non-use values (Gray 2000; Holden 2006). Moreover, earlier justifications for supporting the arts, which had been premised on aesthetic judgement, intrinsic worth or cultural excellence were swiftly way-sided in favour of things that could be more easily quantified and audited. Audience sizes, ticket revenues and percentage contribution to GDP displaced more amorphous and totalising objectives like bolstering the national prestige. In sum, a narrower and more instrumental understanding of art value prevailed, one that downplayed the idea of aesthetics and culture having value in their own right, and instead making state investment in the cultural sector conditional upon its ability to achieve other ends and goals.

This instrumental logic continued shaping the cultural policy landscape and discourse in the decades that followed. It was retained, for example, as part of the New Labour government's modernisation agenda after 1997. Rather than challenge the legacies of NPM, Tony Blair's government doubled down on existing economic rationalisations for arts subsidies and added to them with further instrumental arguments about the positive role that the arts could have in tackling social exclusion and immobility (Bonham-Carter 2017).

The rise of an 'audit culture' has not been limited to the national level. The long arm of NPM has also reached local government and its modes of service provision. In the wake of the financial crisis and post-2008 funding cuts, instrumental logics have combined with a sort of mission creep, whereby local authorities have been forced to devise creative strategies to try and maintain existing operations in the face of declining resources. In this context, local government investments in culture are now expected to contribute to a much wider range of social and economic objectives than was traditionally required. Moreover, the burden of programme and project delivery has gradually shifted onto civil society organisations and volunteers.

Cultural policy scholars have highlighted a wide range of problems with deciphering 'value' based on the instrumental and ancillary benefits of culture. To quote Holden (2004, p. 17) "ways of demonstrating benefit have become tortuous, 
employing 'complicated and contested assessments of causation'. Worse still, 'those things that [are] easy to measure tend to become objectives, and those that [are not, are] downplayed or ignored'. This presents a particular difficulty for the cultural sector, where much of what is done is not 'easy to measure'." The result is that culture becomes stuck in 'service agent' mode, expected to achieve a range of extraneous and ancillary purposes and in doing so, generating ever-growing expectations that are ultimately impossible to meet. Moreover, establishing a causal link between culture and possible economic or social benefits is often challenging since such relations are complex, may emerge over variegated timeframes and be compounded or confounded by a multiplicity of intervening factors.

What emerges from the cultural policy landscape then is a reasonably unified view of the need to reframe discussions about cultural value in order to push beyond methods and perspectives that normalise instrumental and transactional reasoning. Ladkin, McKay and Bojesen (2016) view the rise of instrumentalism and its attendant 'audit culture' as symptomatic of a wider hollowing out of the state and weakening of social bonds under neoliberalism. Following this view, the problem isn't just that culture is seen in instrumental terms but that this instrumentality must be at the service of the market. In effect then, there has been a dual narrowing. Firstly, of cultural value to putatively instrumental needs; and secondly, of instrumentality itself to the pursuit of the economic goals of rationalization and efficiency (as opposed to more amorphous social, civic or political goals). Advocating for resistance to these processes, Ladkin, McKay and Bojesen argue that we should be doing away with the language of 'value' altogether. Whilst many agree with their diagnosis, some scholars remain wary of abandoning the language of 'value' without developing an alternative lexicon for articulating the worth of cultural practice (Belfiore 2004; Holden 2004, 2006; Sandel 2012a, b).

With this aim in mind, Sandel revisits the language of intrinsic value. Lamenting "the expansion of markets, and of market values, into spheres of life where they do not belong" (Sandel 2012a, b, p. 7), he emphasises how certain goods and sectors yield other 'inner worths' that extend beyond their commercial or exchange value. Sandel is not wrong in this observation: cultural practice is of course irreducible to markets and metrics. However, part of the trouble with identifying and articulating what lies beyond these markets and metrics is that advocates of intrinsic cultural value rely on a weakened 'value vocabulary'. Whereas in the past philosophers related the so-called 'inner values' of the arts to beauty, truth, delight and transcendence, the ostensible universality of such experiences has now been largely debunked. Post-structural and decolonial interventions have demonstrated that cultural experiences are temporally and geographically specific (Bennett 1997; Holden 2004).

Of course, these changes do not imply a complete loss or destruction of the vocabulary on value. Rather, the issue here relates to which voices and perspectives get heard. Over the last decade or so, feminist and marxist scholars have made several productive interventions in this space, highlighting alternative paradigms and extended criteria for articulating value. Among these are Gibson-Graham's work on "diverse economies" (see Gibson-Graham 2008, 2014), emerging scholarship on the practice(s) of "commoning" (see Bresnihan and Byrne 2015), as well as Campos, Zapata and Ordonez's (2020) and Shaw's (2019) scholarship on the slow urbicide 
of austerity and the urgency of articulating a "right to the world" which places value in everyday social infrastructures. As we can see, articulations of value that push beyond the instrumental/economic do exist. However, they rarely make it into the policy sector, instead remaining confined to the status of 'alternative discourses/ practices'.

So, just what is the takeaway from all of this? It seems that, whilst there is a good case for revisiting the lexicon of 'inner value', such arguments need to be divorced from the universal and rather re-envisioned in the light of experience and situated practice. Moreover, in the wake of austerity and attendant pressures to rationalise cultural interventions in strict, temporally bound, economic terms, it is important to carve out space for the discussion and recognition of more amorphous instrumental values, keeping in mind that some cultural practices will by nature entail fuzzy, imprecise, temporally confounding and even transversal lines of causality. In the sections that follow, we seek to demonstrate how such a broadening and deepening of the operational concept of value can help us to better understand what members of the public gain from involvement in 'twinning'.

\section{The case of twinning}

Over the last fifty years, the practice of twinning has broadened, deepened and transformed such that it now encompasses a wide variety of economic, social and cultural practices underpinned by a logic of exchange (Ryan 2020a, b). Cosmopolitan thinkers including Zelinsky (1991) applaud these developments, arguing that the popularity of twinning signals the shift towards a truly global society. However, not everybody has been as convinced of the value of these translocal connections. Papagaroufali (2005, p. 336), for example, describes twinning projects within Europe as exercises in cultural and historical "indoctrination", a statement that belies a strong euro-scepticism and concern about the assimilation or erosion of local and national identities. Media commentators have also been less than effusive in their analysis. Tom Brown of the $B B C$ writes of town twins: "Most places have got one. Some even have several. But many people know nothing about them" (Brown 2013). Meanwhile, in an article for The Guardian, Rob Self-Pierson (2012) asked: "is there a point to twin towns?", a question that prompted him to embark on a year-long road trip across Europe, meeting with representatives of 45 of England's partner localities. The journey provided an opportunity for him to reflect on the complexities of his own identity as an Englishman and a European, together with a chance to appreciate the distinctive character and history of each relationship. Nonetheless, his somewhat regretful diagnosis was that twinning may now be on the ebb in the UK. This aligns with observations made by Lord Anderson of Swansea during a debate in the House of Lords. "There are a number of reasons for [the decreasing uptake of twinning]", Anderson contends. 'There is the austerity-[twinning] was perhaps the first cutback made by local authorities; people are travelling more; some have sought to politicise it-Cuba, the West Bank; and there is the amount of councillors going 
to exotic locations at council tax payers' expense" (Hansard 2014, Volume 753, Column 194).

Anderson speaks with conviction. Yet, it is worth examining each of his claims a little more closely. A healthy cynicism towards so-called 'junkets' and 'jollies'unnecessary travel and indulgence at the taxpayers' expense-is well justified. All officials should exercise prudence with respect to their uses of public funds. Whilst some individual councils or councillors have attracted criticism for their travel expenses, research by Clarke (2009) suggests that, when it comes to town twinning, there in fact appears to be "little evidence of jollies, junkets, and jamborees" undertaken by local councillors. Rather, the evidence from over sixty interviews that we have conducted with twinning actors between 2017-2020 suggests that council led trips are usually undertaken for one or two reasons: (i) technical exchange; or, (ii) municipal diplomacy. Examples of the former have included delegations of housing officers, waste planners and electoral observers travelling to meet with counterparts and trade on ideas, expertise and best practice. The latter includes more ceremonial affairs such as mayoral visits, receptions and gifting. Whilst such activities may appear to be lavish or excessive to some observers, our research suggests that they can play a very important role in terms of soft power and persuasion. An enthusiastic welcome and expression of generosity can bring partner communities closer together, signalling an openness and willingness to cooperate on matters of mutual concern. Meanwhile, lack of interest or lack of reciprocity can be taken as a slight or insult, with knock-on implications for the partner's willingness to engage in future joint ventures or collaborations. "Pete" works for an organisation that facilitates twinning with towns and cities in East Asia. He underlines how, over time, British local authorities have come to see these relationships in an increasingly transactional light. This has posed challenges for new and existing relationships, with British partners sometimes coming across as disinterested, rude and even "mercenary" in their approach.

We also find Anderson's argument about the 'politicisation' of twinning to be a bit of a misnomer. In an age characterised by growing disengagement with many aspects of formal politics and heightened distrust of politicians and parties (Parliamentary Office of Science and Technology 2015; Flinders 2015), it is unclear why the pursuit of twinning links for more overtly political purposes should be seen as an inherently negative development. Examples of twinnings that have emerged as part of movements for international solidarity with Nicaragua in the 1980s, or as part of the anti-apartheid movement in the early 1990s suggest the presence of an active civil society concerned with the conduct of government at home and abroad. As political thinkers since de Tocqueville have reminded us, an engaged civil society is the bedrock of a strong democracy, allowing for enhanced transparency and accountability with respect to the actions (and inactions) of government. More to the point, the post-war twinning project, premised on engineering everyday forms of peacebuilding, was itself undoubtedly political in intent. As such, we have to wonder if this scepticism towards 'politicised' twinnings is more a product of the type of politics - arguably a more radical project of anti-imperialism and anti-racism—that they represent than the problem of 'politicisation' per se? 
Similarly, the claim that more opportunities for international travel leads to less interest in twinning requires some unpacking. The United Nations World Tourism Organization (UNWTO) estimates that, between 1950 and 2017, international tourist arrivals increased from some 25 million to 1.4 billion, with the latter generating US\$1.6 trillion in global export earnings and 10\% of global GDP (UNWTO 2019). For several decades, twinning happily co-existed with a growing travel industry, so we have to ask, what exactly has changed, if anything? Hall (2011) offers some clues, writing that recent decades have been marked by a "radical change in the rate, nature, and the promotion of consumption" in the area of international travel. What he points to is not a quantitative but rather a qualitative shift in which an accelerated commodification of landscapes, cultures and localities has been taking place. Key to this process is the presence of a well-oiled commercial machinery-guidebooks, websites, documentaries, social media accounts and influencers-that promote novelty, difference and discovery to subjects that are figured foremost as consumers (Lisle 2016). The consequence of this is comparably less enthusiasm for alternative modes of travel that focus on building sustained relations with one place over time and investing in the ecological and social fabric of that place. Moreover, whilst the observation that 'people are travelling more' may well be true, it fails to interrogate who is travelling more and how positionality vis-à-vis global border regimes determines such mobilities, making the opportunities for travel available to some and offlimits to others.

All in all, we find Anderson's first suggestion-austerity-to provide the most compelling entry point for a discussion about the waning influence of twinning in the UK context. In the last decade, cuts to local government funding have had a significant effect in terms of support available to twinning associations. After the 2008 financial crisis, recession and subsequent collapse in government revenues, the UK's public deficit rose significantly. Public spending increased from around $41 \%$ of GDP to 48\% of national income between 2006-2007 and 2009-2010, and revenue fell to 37\% (Ferry and Eckersley 2011). Between 2010 and 2017, the government reduced funding to local authorities in England by $36 \%$ as part of its ongoing plans to tackle the deficit (National Audit Office 2014, 2018). The effect of these cuts has been an ever more challenging funding environment, in which local authorities must continue to deliver a range of frontline education and care services which they have a statutory obligation to provide.

Within this context, support for cultural and leisure-based activities has seen a dramatic rollback. Where, in the past, a good proportion of councils employed an in-house twinning officer, these individuals "were often the first ones [to go] when the budget cuts came-or-they had their job roles changed and they became European officers, international officers or similar", stated "David" who works in one of these council roles. Among those that have retained their jobs, many have been required to go part-time and others have had their portfolios widened extensively such that twinning has become only a very small proportion of their job. Moreover, reporting demands on volunteer-led twinning associations have increased and there is a heightened pressure to justify any spend on twinning activity in terms of future economic returns to councils. The administrative burden linked to fundraising, organising international exchanges (and more) with partner communities can weigh 
heavily on volunteers who, when interviewed, reported high rates of overstretch and 'burnout'. As such, groups that have had continued access to a dedicated twinning officer have tended to benefit from this extra capacity in a variety of ways. They may receive support with funding applications to regional (EU) or charitable bodies, as well as assistance with organising and promoting events. Moreover, as twinning officers normally work with several twinning associations at once, there are greater opportunities for these groups to dialogue and share best practice.

In the sections that follow, we continue to examine just what might be-or has been-lost with the recent set of manoeuvres aimed at streamlining, rationalising and reducing costs. We ask: just what is the value of twinning? And, more crucially, how should we conceptualise it?

\section{Just how should we think about the value of twinning?}

Whilst we identify with Ladkin, McKay and Bojesen's argument for resisting the language of 'value', the prevailing challenges faced by twinning, linking and friendship associations do not warrant us the privilege of stepping outside of the debate altogether. On the one hand, without establishing an appropriate framework for acknowledging and discussing the value of their activities, these civil society actors face a further peeling-back of resource. On the other hand, when pressed to rationalise their own existence, as has often been the case where local government is involved, they may find themselves tempted to turn to the forms of 'bullshitting' which Belfiore (2009) associates with attempts to evidence 'impact' for the sake of advocacy. In what follows, we draw upon three years of research in order to propose a qualitative four-pronged typology of against which many different modes and manners of translocal partnership can be mapped. Just how should we think about the value of twinning? We argue that twinning activity is best understood as having instrumental, intrinsic, cumulative and generative-productive dimensions of value. The four dimensions of twinning value are not mutually exclusive. Rather, they frequently overlap and feed into one another, revealing the messy reality of material and affective mores that motivate and fuel twinning practice. Below, we trace the contours of these different dimensions of value, aiming to signpost—albeit in a limited way-how and where they begin to intersect, correspond and converge.

\section{The instrumental value of twinning}

The topic of instrumental value was introduced in Part 2 with respect to wider debates taking place within cultural policy studies. Instrumental value is thought to accrue when activities are undertaken for a purpose and thus achieve some tangible or intangible goal. Much in line with patterns seen in the broader arena of cultural policy, the qualitative data that we have gathered between 2017 and 2020 suggest that twinning too has become the casualty of an 'audit culture' designed to reign in local government spending and pivot existing resources towards the search for 
new revenue streams. As a result, much greater onus has been placed on 'the economic offer' of twinning, whose instrumental value is generally conceived in terms of revenues derived from business and trade links. This 'economic offer' has been the main motivation behind recent twinnings with towns and cities in fast growing and emerging economies like China and India.

Sino-British twinning has accelerated considerably in recent decades. Wu, Zhang and Wang (2016) draw on data held by the China International Friendship Cities Association (CIFRA) to identify some 52 formal partnerships that were signed into force between 1980 and 2015, making Chinese cities one of - if not the-most popular choice(s) for Council-endorsed links. The authors make several interesting observations about Sino-British town twinning. The first is that there has been considerably more interest in and uptake of Chinese partnerships by Northern English towns and cities than those in the South. This is attributable, they argue, to the continuing challenges of de-industrialisation, whereby former centres of British manufacturing have found themselves looking beyond national government for significant capital injections and creative new pathways to growth. In this respect, the UK appetite for Sino-British twinning can be said to magnify a series of fissures: between national and local government; North and South; tertiary and secondary economies. Secondly, in spite of the appetite for these trade-inspired twinnings, the authors observe that there is, in fact, rather limited evidence of serious financial return, particularly for the younger links. Rather, economic benefits tend to accrue incrementally and in the context of those partnerships with a pre-existing social, civil and cultural base (Ibid.).

The Sheffield-Chengdu relationship is an instructive example of what can go wrong when economic rationalisation, public-private partnerships and business logics crowd out other motivations for twinning. In 2016, the two cities signed a 60 -year MoU premised on wider plans to regenerate and 'make-over' key sites in Sheffield City Centre. Included in these plans were the transformation of Sheffield's Central Library into a luxury hotel and conferencing centre. The twinning was lauded as having secured the "biggest Chinese investment deal outside London" with the Sichuan Guodong Construction Group (SGCG), a private real estate developer headquartered in Chengdu, pledging funds in excess of $£ 1$ bn. However, by 2019 , an initial tranch of $£ 220$ million was yet to materialise. After a great deal of fanfare, and some $£ 40,000$ of Sheffield council funds sunk during the planning stages (Burn 2019), the partnership was curtailed. The Chinese Government's introduction of new capital controls and regulatory measures to prevent Chinese overseas investments placing downward pressure on the value of the yuan had altered market conditions. In the new climate, the capital projects no longer offered a viable return for SGCG. To use the words of one of our interviewees, such transactional or "mercenary" approaches to twinning can carry high risks.

The emphasis on the economic returns of these translocal partnerships not only detracts from intrinsic benefits (discussed further below), it also risks downplaying the importance of other instrumental benefits that have been associated with twinning practice. Returning to the example of Sino-British twinning, it is notable that both the Chinese and British national governments have used city twinning as a stepping-stone or device to enhance bi-lateral relations, public 
diplomacy and 'soft power'. In 2015, for example, then Chancellor of the Exchequer George Osborne delivered a speech in Chengdu encouraging Chinese investment in the Northern Powerhouse. In this speech, he explicitly referenced existing twin links as a foundation for future successful collaboration (HM Treasury 2015). More recently, at the height of the first wave of the Coronavirus pandemic, Chinese twin cities made headlines for shipping much needed Personal Protective Equipment (PPE) to their UK partners. Coming at a time when NHS Trusts were reporting shortages, Chinese "mask diplomacy" sped up the acquisition and direction of vital equipment to hospitals and care homes where it was desperately required (Ryan and Mazzilli 2020). These gestures helped to boost the China's international prestige and image at a time when Chinese bi-lateral relations with the UK had begun to sour.

Besides providing an adjunct to diplomatic and statist goals, twinning and linking have served a surprisingly wide variety of instrumental objectives for public sector bodies and civil society groups. In terms of the former, twinning has been used as a vehicle for technical exchanges in the area of ports and waste management by local councils (One World Link n.d.). Hospital links between the UK and developing countries have been utilised to mutual benefit in the strengthening of organisational capacity and clinical expertise (Gedde 2009; Gedde et al. 2011). Meanwhile school twinnings have enabled the trade in ideas vis-a-vis curriculum development, supported language-based exchanges and provided opportunities to experiment with a more global education paradigm that encourages reflection on global supply-chains, sustainable development, climate change and imperial entanglements (Leicester Masaya Link Group 2018; Licht et al. 2019).

In terms of the latter, twin links have mobilised communities of sentiment in response to natural disasters and crises such as earthquakes, hurricanes and pandemics. They have also galvanised communities of solidarity to counter the threat of-inter alia-foreign intervention, dictatorship and militarism in their partner communities. The first and perhaps most significant examples of "solidarity twinning' were those that emerged in support of Nicaragua after the 1979 Sandinista Revolution. Within this framework, delegations of British volunteers travelled to the Central American state to assist with projects in education, healthcare, agriculture and construction. Against the backdrop of the US-backed Contra War, twin towns helped to keep the British media spotlight on the political events in Nicaragua, amplifying concerns about the conduct of US Foreign Policy in Latin America. The practice of linking with communities under siege was later taken up by anti-apartheid activists linking with populations in African National Congress (ANC) supporting areas of South Africa as well as those exiled in Mozambique; and more recently the practice has been taken up in the context of Palestinian struggles against annexation and everyday militarism in the Occupied West Bank. Normally driven by the concerns of political activists and social movements, 'solidarity twinnings' can be understood as expressions of resistance to local and/or global configurations of power. The public act of connecting with a community under duress has rhetorical power. It sends a message of recognition to those under threat; it also signals to the wider world that an injustice is unfolding and places a spotlight on human rights abuses. Additionally, solidarity 
twinning can become a conduit or channel for practical assistance: fundraisers, skills-based delegations, and international mobilities can all make a meaningful contribution to the material conditions of a partner community (Ryan 2020a, b). In the longer term, as community connections enable shared testimonies to amass, these partnerships may even come to provide an instructive source of popular social history.

\section{The intrinsic value of twinning}

Whilst many-perhaps the vast majority of - twinning activities emerge due to some kind of instrumental need or purpose, it is important to acknowledge that some of the benefits wrought from twinning may also be intrinsic in character. The intrinsic value of something is said to be the value that that thing has 'for its own sake,' or 'in its own right.' Historically, aesthetic philosophers related the concept of intrinsic value to supposedly universal experiences embodied in the perception of beauty and the progress of truth. However, contemporary writers such as Walmsley and Oliver (2011) and Holden (2004) point out the flaws of such foundationalist stances and instead encourage us to re-envision intrinsic value in the light of situated experience. With respect to twinning practice, the intrinsic benefits derived by participants are most readily associated with affective, sensory and emotive experiences. These experiences can emerge in response to some kind of concrete gesture or moment of happening, such as an act of gifting, commemoration or co-creation (of art, music, artefact). But equally they may include the feelings of warmth and worth that are associated with having and holding another person or groups of persons dear to us. In other words, the feelings of mutual care and enjoyment that are embodied in the expression of friendship.

In the Nicomachean Ethics, Aristotle described three main forms of friendship, inspired respectively by impulses of utility, passion and virtue. Friendships of utility are those instrumental relationships that we cultivate to help us achieve other goals. Friendships of passion are those that embody the intimacy and physicality that is shared between lovers. Meanwhile, friendships of virtue imply a kind of mutual affection which sees us loving our friends completely and in spite of their flaws. This third image of friendship sets a kind of normative standard to which all interpersonal relationships should and might aspire: here friendship is valued for its own sake rather than in expectation of future benefits of some kind. Whilst many of the twinning arrangements described in the previous section might be understood plainly as friendships of utility, it would be remiss to neglect the strong prevalence of friendships of passion and virtue among the wider landscape of twinnings that we have surveyed. Twinning delegations and exchanges have spawned a variety of transnational romances and camaraderies; deep and lasting interpersonal connections that have persisted for many years, in some cases outliving the twinning arrangements themselves. As one participant put it, "[Being friends] means that we're equal partners and look upon each other equally rather than as a kind of 'us' and 'them' ... for twinning to work, you have to have a mutual respect for each other, irrespective of 
wealth or nationality or position in society. Simply, we respect each other's way of life and we embrace it together".

Love and mutual affection between friends are indeed valuable in their own right. However, attempts to enforce a rigid analytical separation between Aristotle's three modes of friendship and by extension, between the intrinsic and instrumental, are in practice somewhat misleading. Experience tells us that the most fulfilling passionate relationships can be built upon existing friendships of virtue; and, that passion and utility sometimes go hand in hand. Nonetheless, as Roshchin (2014) argues, in the Western philosophic canon these analytical categories and distinctions have largely held up, with friendships of virtue and passion relegated to the private sphere and friendships of utility more readily understood as a basis for the public practice of politics and diplomacy. A detailed look at the practice of twinning exposes these categories of public/private, instrinsic/instrumental as fuzzy and unstable. For example, communities of friends are unlikely to sit passively by in the wake of an external threat or natural disaster befalling those that they love completely and as equals. Rather, the strong affective and social bonds embodied in friendships of virtue and passion often serve as the fuel, scaffold and/or stimulus for taking up more instrumental actions. Friends will, where possible, seek to defend, support, or protect one another. Thus, when the 2014 Ebola virus outbreak hit communities in Sierra Leone, threatening lives and livelihoods, long-time friends in the United Kingdom rallied to their aid. The One World Link which connects the districts of Warwick and Bo set up an emergency fund to assist families in need and helped to establish washing and waste collection points at local schools. Meanwhile, the Hastings Sierra Leone Friendship Link connecting Hastings UK to Hastings SL sent several shipments of medical equipment to the local community health centre in Hastings SL. As documented in The Lancet, Sierra Leone's response to the Ebola emergency was compromised by a fragile health system with scant resources, limited infrastructure, and one of the world's severest shortages of health-care workers. Despite support from donors and partner organisations, specialist Ebola treatment units were only able to provide around $60 \%$ of the beds needed as the outbreak neared its peak (Michaels-Strasser et al. 2015). In this context community health centres became vital for removing infected individuals from the community and providing access for other acute medical needs. As soon as travel restrictions were lifted in 2016, a delegation from Hastings UK headed to Hastings SL to assess the virus' socio-economic impacts and offer support to community leaders in putting together a comprehensive recovery strategy.

What we can take from all of this is the lesson that the intrinsic value of friendship may coalesce with and actually enhance other aspects of twinning value. The trust, care and affection that is implied by friendships of virtue can form a solid basis for future moral, political or potentially even commercial action. Returning to the findings of $\mathrm{Wu}$ et al. (2016), this may help to explain why economic benefits tended to accrue in the context of the older Sino-British partnerships and in those with a pre-existing social, civil and cultural base. This of course also directs our attention to the fact that twinnings-and the 
relationships that ultimately sustain them-develop and evolve over variegated timeframes and in response to external events, opportunities and constraints. As such, any assessment of the public value of twinning must also be attentive to its temporal dimension, which we turn to next.

\section{The cumulative value of twinning}

Attention to the cumulative value of twinning draws the question of temporality into sharper focus. Temporality refers to the ways that individuals and groups inhabit, experience and operate within a specific historical period or location. The notion of divergent temporalities recognises the fact that human beings do not all organise and experience time in quite the same way. Indeed many different calendars have been developed over the millennia to help societies to situate their existence and there remain some forty calendars in use around the world today. Whilst those of us following the Gregorian calendar may all agree that we live in the twenty-first century, we do not all experience this historic era the same way either. Perceptions of time interact with emotions and events. Periods of boredom and drudgery often feel as though they last much longer than periods of excitement and activity. For all of us, there will be landmark events - deaths, births, traumas, victories-which stand out as formative experiences to which we return again and again in ways that shape our future lives. When we speak of the cumulative value of twinning then, we do not just refer to the added utility gained from twinning over a predictable and undeviating progression of time. We also call attention to the asynchronous temporalities that are encapsulated and reproduced within twinning practice and the ways that value or utility often emerges in a punctuated and non-linear fashion ushered on by key events and experiences.

The asynchronous temporalities of twinning are perhaps best illustrated in the comparison between the experiences and approaches of local council bureaucracies and community-led twinning associations. For local councils, twinnings come to exist only when an agreement or MoU has been signed into force by officials. 'Twinning work' takes place according to timeframes and budgets established within the council structures and it ceases when councils remove or redirect resources. Engagement with twinning is shaped by bureaucratic time. For the community activists and volunteers that form the twinning associations on the other hand, these community partnerships usually begin months or even years before they are submitted to the local councils for endorsement. The commitment that members of twinning associations make in order to support and sustain their partnerships may cut across their work and leisure time, pervading everyday life and routines in a more organic way. As a set of voluntary activities, twinning is not delimited by contractual obligations or imperatives relating to 'the working week'. Moreover, the activities of twinning associations rarely stop when local councils decide to take a step back. Instead, the relationships may continue to display a dynamism or afterlife, fuelled in large part by the mutual affection of their members. Much of this care-based labour goes on unseen and unaccounted. 
The divergent temporalities of twinning are also evidenced in the way that the utility of these relationships amass. More often than not, the value of twinning does not emerge in the continuous and easily quantifiable manner anticipated by the narrow accounting schedules and growing audit culture of contemporary British local authorities. Rather it tends to amass in more disjoint, uneven, and indeterminate ways that reflect the complex real-world interplay of events, discourses, emotions and perceptions. Through our interviews for example, we came into contact with dozens of individuals who had visited their partner community as part of a twinning delegation. Sometimes these were school based exchanges that they had participated in as children. For others it was a journey they had undertaken as part of a gap year, for leisure, or as part of a workplace exchange. For many of these participants, the full value of the visits only came into clear focus some time afterwards as they reflected on the ways that their past experiences had come to shape their later lives. Several articulated how the experience of connecting intimately with another culture, people and locality had initiated a gradual shift in their worldview, priorities and/or aspirations. This shift was sometimes compounded by other life events: sometimes it was hastened or honed in line with concepts, meanings or values embodied in popular discourse. In some cases early twinning experiences had ramifications for the career trajectories and political leaning of the participants and in others it affected their tendencies towards charitable giving and future international travel.

Implicit in the discussion above is the observation that, whilst the value of participating in a twinning activity might reveal itself in gradual or unanticipated ways, it can also spur on processes of social and cultural change. This provides a glimpse into our fourth and final dimension of twinning value. That is, the generative-productive work of twinning practice.

\section{The generative-productive value of twinning}

The generative-productive value of twinning relates to the ways that it can open up new possibilities and pathways for social, economic and political action. We count at least three different levels at which this can-and has-occurred: the global, the subnational and the individual or micro-level.

Firstly, twinning can be regarded as a 'generative' practice in the sense that it has directly or indirectly influenced the emergence of other models and examples of subnational cross-border cooperation. Growing literature on globalisation and multi-level governance emphasises the 'unravelling' or 'untangling' of nation states in the twenty-first century and the rise of towns and cities as "critical engines driving the global economy, global information flows, and the worldwide mobility of goods and people" (Acuto et al. 2016). In this context, cities are increasingly recognized for their distinct role in international relations and, in recent years, there has been a significant growth in the number of so-called 'city networks' that have emerged to tackle contemporary governance challenges in ways that bypass or circumvent national governments. Key examples include the $\mathrm{C} 40$ cities initiative to tackle climate change, the United Cities and Local Governments (UCLG) group and 
the Rockerfeller Foundation 100 Resilient Cities network. These and other experiments in city networking have been conceptualised as examples of 'paradiplomacy' (Kincaid 2002; Tavares 2016), a process by which the constituent units of a sovereign state are able to conduct their own diplomatic engagement with another state or its constituent units for the pursuit of their own interests (Chatterji and Saha 2017). The concept of 'paradiplomacy' aims to capture the zeitgeist and a great deal of the literature emerging from this perspective frames subnational diplomatic activity as something qualitatively new for the twenty-first century. However, subnational diplomatic cooperation is by no means 'new' to the world of global politics and international society. Indeed, paradiplomacy is perhaps better understood as an outcrop, product or extension of earlier experiments in town twinning and sister-city partnerships (Cities Today 2014; Hansard 2014; Chatterji and Saha 2017). It merely marks the latest phase in the continual evolution of cross-border forms of cooperation.

Secondly, evidence of the generative value of twinning can be found at subnational level where twinning often spurs the development of related projects and spin-off initiatives such as new charities, NGOs, and schools or hospital links. This point recalls what geographers define as 'hub' or 'network' effects: where links initially formed by a core group (in this case, the twinning association) accelerate the formation of other connections between the two communities. We came across numerable examples of this in our research, including Twin Cafè, an initiative that emerged from the formal twinning between Sheffield and Estelì (Nicaragua). Twin Cafè came about after students from The University of Sheffield travelled to Estelì on a twinning delegation. There they met with local coffee cooperatives and several of the students had the idea of creating a fair-trade coffee company that would benefit both communities. The Sheffield group started importing green coffee from a small farmer's cooperative in Miraflor, an elevated region just outside of Estelì. They arranged for it to be roasted, packaged and sold in Sheffield. The Twin Café initiative successfully expanded and now supplies over twelve Sheffield stockists, with proceeds repatriated to Nicaragua to support various social projects in Estelì (Twin Café 2020).

A third and final aspect of twinning's generative value relates to the ways that these international partnerships function as sites of 'productive power' that entail possibilities for resisting the prevailing order of things. The work of Foucault (1980) and especially his depiction of power as a relation between forces can help to make sense of this dynamic. Railing against conventional understandings of power as episodic, negative and oppressive, Foucault sought to demonstrate that power also works in an everyday, productive or creative sense. In other words, power is diffuse and present in all settings and situations. It is embodied in and reproduced by metanarratives or 'regimes of truth' (Rabinow 1991); it is also present in the production of alternative discourses or 'micro-narratives' that challenge, destabilise or unsettle the status quo. The latter-micro-narratives that challenge the status quo-are foundational to twinning practice. The post war twinning project was premised on the creation of translocal connections that unsettled then-dominant discourses of enmity and antagonism between neighbouring European states. The production of alternative narratives and worldviews has continued to play a central role with respect to later experiments in twinning for political solidarity for example, wherein the 
decision to connect with a population overseas often embodies an organised and collective form of opposition to a particular local and/or global configuration of power relations. Indeed a great number of today's twinnings and sister city relationships are underpinned by ideological connections and/or humanitarian concerns that are essentially at odds with official supranational, national or city political agendas and policies (Zelinsky 1991 cited by Jayne, Hubbard and Bell 2013). These contrarian examples offer subtle hints at a world that might be otherwise. In sum, when we are encouraged to pay closer heed to the generative-productive value of twinning, we are forced to confront not just what is, but also what is immanent or yet to become.

\section{Conclusion}

Belfiore's 2015 article "Impact, Value and Bad Economics" begins and ends with a plea for a collaborative effort to resist the economic doxa that has come to govern how British policymakers and publics conceive of 'value' in the arena of the arts and cultural policy. This article takes up her call through a re-examination of the related practice of twinning. Twinning, it is argued, is a dynamic and amorphous cultural and social practice that has broadened, deepened, and transformed considerably from its post-war foundations. In recent years it has-like many other activities within the UK cultural policy sector-fallen under the ambit of NPM, cuts and costsaving measures at the local government level. These processes have centred transactional reasoning and a neoliberal audit culture in the allocation of public resources with the effect that many twinning activities have been defunded, abandoned and/ or reconfigured as opportunities for business and trade creation. Our paper retraces these shifts and seeks to highlight what has_-or might be-lost in light of them. It argues that, under the current modus operandi, local governments in the UK ultimately fail to account for some of the most important aspects of twinning value, as evidenced in our research.

In this paper we identify four key dimensions to twinning value: the instrumental, intrinsic, cumulative, and generative-productive. The 'instrumental' refers to value that emerges when activities are undertaken for a purpose, thus achieving some tangible or intangible goal. Twinning has been pursued for the widest range of purposes, from pedagogic experiments in global education to peacebuilding and political solidarity. However, in recent years, many British local authorities have placed a heightened onus on the 'the economic offer' of twinning at the expense of other social, cultural and political gains. The risk of following this "mercenary" strategy is not only that a wide array of 'pro-social' community-based pursuits become waysided in favour of courting business leaders but also that the manifold synergies between trade creation and civic, social or cultural activities are themselves missed. The 'intrinsic' dimension of twinning value encapsulates the notion, expressed by many of our participants, that connecting with a community overseas has worth in and of itself. That is to say, twinning can-and is-sometimes undertaken on account of love, care and amity, rather than on the promise of some future gain. However, the strong affective and social bonds implied by such relationships can sometimes fuel more instrumental activities, such as rallying material or rhetorical 
support when friends and loved ones are perceived to be in need. Our discussion of the 'cumulative' value of twinning sought to draw attention to the asynchronous temporalities that are encapsulated and reproduced within British twinning practice; and, the ways that perceptions of worth are often spurred by events and discourse. In other words, the value of twinning does not emerge in a steady, consistent and predictable manner. Rather it amasses in uneven and irregular patterns that reflect the enormous diversity of twinning relationships and the incredibly complex real-world interplay of events, discourses, emotions and perceptions. The final dimension of twinning value that we sought to illuminate in this paper is what we have termed, the 'generative-productive'. This refers to the ways that twinning can unlock new pathways for social, economic or political action. We outlined three levels of analysis where it is possible to observe the generative-productive worth of twinning activity. Firstly, in the ways that twinning has directly or indirectly influenced the emergence of other models of subnational cross-border cooperation. This may be seen in the rise of city networks and 'paradiplomacy' in particular. Secondly, at the subnational or local level where twinning partnerships have often generated an array of further connections including new charities, NGOs, commercial activities, schools and hospital links. Thirdly, we pointed to the ways that twinnings may function as sites of 'productive power' (qua Foucault 1980) capable of generating micro-narratives that challenge the status quo.

Our research suggests that it is methodologically confounding and potentially even reductive to privilege any one of these four dimensions of value because-in the manner of a four-circled Venn diagram - they continuously overlap and reinforce one another. For instance, the cumulative effects of twinning on participants' life decisions can be observed over many years, giving way to generative effects such as the birth of new projects, links or commercial activities. Our survey of twinning practice leads us to the conclusion that, not only does the value of this increasingly maligned vernacular practice push well beyond the current economic doxa, but its overlapping instrumental, intrinsic, cumulative and generative-productive forms of worth make it uniquely rich as a site and subject of research in the British sociopolitical context.

Acknowledgements This work was supported by the Economic and Social Research Council [grant number ES/R004137/2] as part of its New Investigator scheme. The authors wish to thank Queen Mary University's School of Politics and International Relations for its support in realising the wider project on the evolution and value of twinning. They are also grateful to the editors at British Politics and two anonymous reviewers who provided extremely helpful feedback on an earlier draft of this article.

\section{References}

Acuto, M., et al. 2016. 'City Diplomacy' and twinning: Lessons from the UK, China and Globally. Future of Cities: Working Paper, Foresight, Government Office for Science. https://assets.publishing.servi ce.gov.uk/government/uploads/system/uploads/attachment_data/file/545780/gs-16-13-future-ofcities-diplomacy-uk-china-twinning.pdf. Accessed 1 July 2020.

Anderson, E. 1995. Value in ethics and economics. Boston: Harvard University Press. 
Arts Council England. 2014. The value of arts and culture to people and society: an evidence review. https://www.artscouncil.org.uk/sites/default/files/download-file/The_value_of_arts_and_culture_to_ people_and_society_an_evidence_review.pdf. Accessed 1 July 2020.

ArtsQueensland. 2014 (September 4). Measuring social value in the arts. https://www.arts.qld.gov.au/aqblog/measuring-social-value-in-the-arts. Accessed 1 July 2020.

Australian Expert Group in Industries Studies (AEGIS). 2005. Social impacts of participation in the arts and cultural activity. e Cultural Ministers Council Statistics Working Group (SWG). https:// www.stategrowth.tas.gov.au/_data/assets/pdf_file/0003/160833/Social_Impacts_of_the_Arts.pdf. Accessed 1 July 2020.

Barnett, M. 1991. The politics of truth. Cambridge: Polity Press.

Beck Jørgensen, T. 1999. The public sector in an in-between time: Searching for new public values. Public Administration 77 (3): 565-584.

Belfiore, E. 2004. Auditing culture: The subsidised cultural sector in the New Public Management. International Journal of Cultural Policy 10 (2): 183-202.

Belfiore, E. 2009. On bullshit in cultural policy practice and research: Notes from the British case. International journal of Cultural POLICY 15 (3): 343-359.

Belfiore, E. 2015. 'Impact', 'value' and 'bad economics': Making sense of the problem of value in the arts and humanities. Arts and Humanities in Higher Education 14 (1): 95-110.

Belfiore, E. and Upchurch, A., 2013. Introduction: Reframing the 'value' debate for the humanities. In Humanities in the twenty-first century, 1-13. London: Palgrave Macmillan.

Bennett, O. 1997. Cultural policy, cultural pessimism and postmodernity. International Journal of Cultural Policy, 4(1): 67-84.

Bonham-Carter, C. 2017. From social inclusion to audience numbers: Art museums in the new public management. In Rhetoric, social value and the arts, 35-48. Cham: Palgrave Macmillan.

Bresnihan, P., and M. Byrne. 2015. Escape into the city: Everyday practices of commoning and the production of urban space in Dublin. Antipode 47 (1): 36-54.

Brown, T. 2013. Twin towns: Do we still need them? BBC News, July 31. https://www.bbc.co.uk/news/ uk-england-23517210. Accessed 1 July 2020.

Burn, C. 2019. Sheffield Council scraps 60-year Chinese deal after promised $£ 220 \mathrm{~m}$ investment never arrives. Yorkshire News, July 9. https://www.yorkshirepost.co.uk/news/politics/sheffield-councilscraps-60-year-chinese-deal-after-promised-ps220m-investment-never-arrives-1753185 Accessed 3 June 2020.

Cities Today. 2014 (May 27). How sister city partnerships can play a new role in a global economy. https://cities-today.com/how-sister-city-partnerships-can-play-a-new-role-in-a-global-economy/. Accessed 1 July 2020.

Campos, M.J.Z., P. Zapata, and I. Ordonez. 2020. Urban commoning practices in the repair movement: Frontstaging the backstage. Environment and Planning A 52 (6): 1150-1170.

Cepiku, D., R. Mussari, and F. Giordano. 2016. Local governments managing austerity: Approaches, determinants and impact. Public Administration 94 (1): 223-243.

Chatterji, R., and S. Saha. 2017. Para-diplomacy: concept and the context. India Quarterly 73 (4): $375-394$.

Clarke, N. 2009. In what sense 'spaces of neoliberalism'? The new localism, the new politics of scale, and town twinning. Political Geography 28 (8): 496-507.

European Commission. 2016. European neighbourhood policy and enlargement negotiations. Retrieved from https://ec.europa.eu/neighbourhood-enlargement/neighbourhood/overview_en. Last accessed 29 Jan 2020.

Crossick, G., and P. Kaszynska. 2016. Understanding the value of arts and culture. The AHRC cultural value project. Art \& Humanities Research Council. https://ahrc.ukri.org/documents/publications/ cultural-value-project-final-report/. Accessed 1 July 2020.

Dahl, A., and J. Soss. 2014. Neoliberalism for the common good? Public value governance and the downsizing of democracy. Public Administration Review 74 (4): 496-504.

Feldman, M.S., and A.M. Khademian. 2001. Principles for public management practice: From dichotomies to interdependence. Governance 14 (3): 339-361.

Ferry, L., and P. Eckersley. 2011. Budgeting and governing for deficit reduction in the UK public sector: Act one 'the comprehensive spending review.' The Journal of Finance and Management in Public Services 10 (1): 14-23. 
Flinders, M. 2015. Political fall-out. Fewer people than ever are planning to vote in the forthcoming general election. What is turning off the electorate? Society Now-ESRC Research Making an Impact 21: 12-13.

Foucault, M. 1980. Power/knowledge: Selected interviews and other writings, 1972-1977. New York: Vintage.

Galtung, J. 1964. An Editorial. Journal of Peace Research 1 (1): 1-4.

Gardner, A., and V. Lowndes. 2016. Negotiating austerity and local traditions. Rethinking governance. In Ruling, Rationalities and resistance, 125-143. Abingdon: Routledge

Gaspari, O. 2002. Cities against states? Hopes, dreams, and shortcomings of the European municipal movement, 1900-1960. Contemporary European History 11 (4): 597-621.

Gedde, M. 2009. The International Health Links Manual: A guide to starting up and maintaining longterm international health partnerships. London: The Tropical Health and Education Trust.

Gedde, M., S. Edjang, and K. Mandeville. 2011. Working in international health. Oxford: Oxford University Press.

Gessen, M. 2020. The innocuous story of Bernie Sanders' trip to Russia. The New Yorker, March 6. https ://www.newyorker.com/news/our-columnists/the-innocuous-story-of-bernie-sanderss-trip-to-russia. Accessed 1 July 2020.

Gibson-Graham, J.K. 2008. Diverse economies: performative practices for other worlds'. Progress in Human Geography 32 (5): 613-632.

Gibson-Graham, J.K. 2014. Rethinking the economy with thick description and weak theory. Current Anthropology 55 (S9): S147-S153.

Gray, C. 2000. The politics of the art in Britain. Cham: Springer.

Hall, C.M. 2011. Consumerism, tourism and voluntary simplicity: WE all have to consume, but do we really have to travel so much to be happy? Tourism Recreation Research 36 (3): 298-303.

Handley, S. 2006. Take Your Partners: The Local Authority Handbook on International Partnerships. London: Local Government International Bureau.

Hansard. 2014. City-to-city diplomacy, March 26. https://hansard.parliament.uk/lords/2014-03-26/debat es/14032679000395/City-To-CityDiplomacy. Accessed 1 July 2020.

Head, B.W. 2008. Three lenses of evidence-based policy. Australian Journal of Public Administration 67 (1): $1-11$.

HM Treasury. 2015. Chancellor speech in Chengdu, China, on building a Northern Powerhouse. Available from:https://www.gov.uk/government/speeches/chancellor-speech-in-chengdu-china-on-build ing-a-northern-powerhouse. Accessed $1 \mathrm{Feb} 2020$.

Holden, J. 2004. Creating cultural value: how culture has become a tool of government policy. London: Demos.

Holden, J. 2006. Cultural value and the crisis of legitimacy. London: Demos.

Hood, C. 1991. A public management for all seasons? Public Administration 69 (1): 3-19.

Jacobs, L.R. 2014. The contested politics of public value. Public Administration Review 74 (4): 480-494.

Jansson, André. 2003. The Negotiated city image: Symbolic reproduction and change through urban consumption. Urban Studies 40 (3): 463-479.

Kincaid, Johan. 2002. Foreign relations of sub-national units: constituent diplomacies in federal systems. In Federalism in a changing world: Learning from Each Other, ed. Raoul Blindenbacher and Arnold Koller, 74-96. Montreal: McGill-Queens University Press.

Ladkin, S., R. McKay, and E. Bojesen, eds. 2016. Against value in the arts and education. London: Rowman \& Littlefield.

Lapsley, I. 2009. New public management: The cruellest invention of the human spirit? 1. Abacus 45 (1): $1-21$.

Leach, S., J. Stewart, and G. Jones. 2017. Centralisation, devolution and the future of local government in England. London: Routledge.

Leicester Masaya Link Group. 2018. Food for thought. http://leicestermasayalink.org.uk/index.php/home/ education-and-resources/food-for-thought/. Accessed 08 March 2018.

Licht, A., I. Pateraki, and S. Scimeca. 2019. If not in schools, where? Learn and practice DEMOCRACY with eTwinning. Brussels: Central Support Service of eTwinning-European Schoolnet. https://files .eun.org/etwinning/learn_and_practice_democracy_with_etwinning_EN.pdf.

Lisle, D. 2016. Holidays in the danger zone: Entanglements of war and tourism. Minneapolis: University of Minnesota Press. 
Michaels-Strasser, S., M. Rabkin, M. Lahuerta, K. Harripersaud, R. Sutton, L.N. Ahoua, B. Ngalamulume, J. Franks, and W.M. El-Sadr. 2015. Innovation to confront Ebola in Sierra Leone: the community-care-centre model. The Lancet Global Health 3 (7): 361-362.

Milbourne, L., and M. Cushman. 2015. Complying, transforming or resisting in the new austerity? Realigning social welfare and independent action among English voluntary organisations. Journal of Social Policy 44 (3): 463-485.

Morris, L. 2020. Humanities for the Humane University. Academic Irregularities. https://academicirregul arities.wordpress.com/2020/01/23/humanities-for-the-humane-university/. Accessed 5 Feb 2020.

Mulcahy, K.V. 2006. Cultural policy: Definitions and theoretical approaches. The Journal of Arts Management, Law, and Society 35 (4): 319-330.

National Audit Office. 2014. The impact of funding reductions on local authorities. https://www.nao.org. uk/wp-content/uploads/2014/11/Impact-of-funding-reductions-on-local-authorities.pdf. Accessed 1 Feb 2020

National Audit Office. 2018. The financial sustainability of local authorities 2018. https://www.nao.org. uk/wp-content/uploads/2018/03/Financial-sustainabilty-of-local-authorites-2018-Summary.pdf. Accessed 5 June 2020.

O'Brien, D. 2013. Cultural policy: Management, value and modernity in the creative industries. London: Routledge.

One World Link. n.d. The waste project continues to grow. http://oneworldlink.org.uk/update-on-thewaste-project/. Accessed 1 Jan 2019.

Osborne, D., and R. Gaebler. 1992. Reinventing Government. Reading, MA: Addison-Wesley.

Papagaroufali, E. 2005. Town twinning in Greece: Reconstructing local histories through translocal sensory-affective performances. History and Anthropology 16 (3): 335-347.

Parliamentary Office of Science and Technology. 2015. Trends in political participation. https://post.parli ament.uk/research-briefings/post-pn-0498/. Accessed 5 Mar 2020.

Pillay, S. 2008. A cultural ecology of New Public Management. International Review of Administrative Sciences 74 (3): 373-394.

Rabinow, P., ed. 1991. The Foucault reader: An introduction to Foulcault's thought. London: Penguin.

Roshchin, E. 2014. Friendship and international order: An ambiguous liaison. In Friendship and international relations, 89-106. London: Palgrave Macmillan.

Ryan, H. E. 2020. Brexit has made town twinning a battleground-but it's always been political. The Conversation. https://theconversation.com/brexit-has-made-town-twinning-a-battleground-but-itsalways-been-political-131965. Accessed 1 July 2020.

Ryan, H. 2020. Twinning for solidarity. Manuscript submitted for publication and under review.

Ryan \& Mazzilli. 2020. From 'mutual aid' to 'mask diplomacy': reflections on Covid-19 and the twinning movement. Mile End Institute Blog. Available from:https://www.qmul.ac.uk/mei/news-andopinion/items/from-mutual-aid-to-mask-diplomacy-reflections-on-covid-19-and-the-twinningmovement---dr-caterina-mazzilli-and-dr-holly-evaryan.html. Accessed 20 Oct 2020.

Sandel, M. 2012. What money can't buy: The moral limits of markets. London: Allen Lane.

Sandel, M.J. 2012. What isn't for sale. The Atlantic 309 (3): 62-66.

Self-Pierson, R. 2012. Is there a point to twin town? The Guardian, April 30. https://www.theguardia n.com/commentisfree/2012/apr/30/is-there-a-point-to-twin-towns. Accessed 1 July 2020.

Shaw, I.G. 2019. Worlding austerity: The spatial violence of poverty. Environment and Planning D: Society and Space 37 (6): 971-989.

Stevenson, D., D. Rowe, and K. McKay. 2010. Convergence in British cultural policy: The social, the cultural, and the economic. The Journal of Arts Management, Law, and Society 40 (4): 248-265.

Tavares, R. 2016. Paradiplomacy: cities and states as global players. Oxford: Oxford University Press.

Twin Café. 2020. Blog. https://www.twincafe.org. Accessed 1 Mar 2020.

UK Parliament Post. 2015. Trends in Political Participation. Note 498. The Houses of Parliament. https:// post.parliament.uk/research-briefings/post-pn-0498/. Accessed 1 July 2020.

UNWTO. 2019. World Tourism Barometer. https://www.unwto.org/unwto-tourism-dashboardbarometer. Accessed 1 July 2020.

Walmsley, B. and Oliver, J., 2011. Assessing the value of the arts. In: Walmsley, B. (ed.). Key issues in the arts and entertainment industry. Oxford: Goodfellow.

Wu, F., F. Zhang, and Z. Wang. 2016. Twinning and contact between British and Chinese cities. Future of Cities: Working Paper, Foresight, Government Office for Science. https://assets.publishing.servi ce.gov.uk/government/uploads/system/uploads/attachment_data/file/545779/gs-16-14-future-ofcities-twinning-contact-britain-china.pdf. Accessed 1 July 2020. 
Zelinsky, W. 1991. The twinning of the world: Sister cities in geographic and historical perspective. Annals of the Association of American Geographers 81 (1): 1-31.

Publisher's Note Springer Nature remains neutral with regard to jurisdictional claims in published maps and institutional affiliations. 